\title{
Influência do exercício físico sobre a proteína de estresse oxidativo Hemoxigenase-1
}

http://dx.doi.org/10.11606/1807-5509202000030523

\author{
Ailma Oliveira da PAIXÃO* \\ Vanessa Azevedo VOLTARELLI* \\ Patricia Chakur BRUM*
}

*Escola de Educacãa Física e Esporte, Universidade de São Paulo, São Paulo, SP, Brasil.

\section{Resumo}

A Hemoxigenase (HO) é uma enzima que atua na degradação/metabolização do grupo heme gerando três produtos: o monóxido de carbono (CO), a biliverdina (BVD) e o ferro ferroso $\left(\mathrm{Fe}^{2+}\right)$. Uma das isoformas da $\mathrm{HO}$, a Hemoxigenase-1 ( $\mathrm{HO}-1)$ vem sendo amplamente estudada devido às suas potentes propriedades protetoras, desempenhando ações anti-inflamatórias, antioxidantes, antiapoptóticas e antiproliferativas, e exercendo funções citoprotetoras em diversos tipos celulares, bem como, em diferentes tipos de lesões em modelo animal e em humanos. A HO-1 é uma enzima induzida em resposta ao estresse celular, sendo estimulada por diversos fatores como: luz ultravioleta, hipóxia, metais pesados, óxido nítrico, citocinas inflamatórias, etanol, prostaglandinas e choque térmico. Além disso, a H0-1 também é induzida em resposta ao exercício físico realizado em diferentes durações e intensidades, conferindo proteção celular e manutenção da homeostase celular pós-exercício. Na presente revisão de literatura, em uma primeira parte serão abordadas a localização e a função da hemoxigenase no organismo e, na segunda parte, os efeitos do exercício físico sobre a $\mathrm{HO}-1$ e sua citoproteção serão abordados levando-se em consideração exercícios aeróbios vs. anaeróbios; exercícios aeróbios agudos (uma única sessão de exercício) realizados em diferentes durações e intensidades; exercício aeróbio crônico (treinamento físico) e exercício físico nas doenças crônicas.

PalavRas-chave: H0-1; Exercício; Citoproteção; Metabolismo.

\section{Introdução}

A Hemoxigenase (HO), inicialmente descrita por Tenhunen et al. ${ }^{1}$, é uma enzima cujo principal papel é a degradação do grupo heme. A mesma possui duas isoformas: hemoxigenase-1 (HO-1) e hemoxigenase-2 (HO-2), as quais diferem na sua sequência primaria de aminoácidos (compartilhando aproximadamente $40 \%$ destes), peso molecular e, consequentemente, em suas propriedades bioquímicas e biofísicas ${ }^{2-7}$. A HO-1 é a isoforma mais amplamente estudada devido à sua capacidade de ser induzida por estresse oxidativo, heme livre e diversos fatores como luz ultravioleta, hipóxia, metais pesados, óxido nítrico, citocinas inflamatórias, etanol, prostaglandinas, e choque térmico ${ }^{7-9}$. Na maioria dos tecidos, sua expressão é relativamente baixa ou indetectável em condiçóes normais de homeostase redox. Entretanto, ela é constitutivamente expressa em células do fígado e em linfócitos $\mathrm{T}$ $\mathrm{CD}^{+} / \mathrm{CD} 25^{+}$, ressaltando sua importância para o sistema imunológico. Já a isoforma $\mathrm{HO}-2$ é constitutivamente expressa nos tecidos, estando onipresente em todo o organismo ${ }^{2,7,9}$.

A degradação do grupo heme é catabolizada pelas duas isoformas HO-1 e HO-2 resultando na liberação de três produtos finais: o monóxido de carbono (CO), biliverdina (BVD) e ferro ferroso $\left(\mathrm{Fe}^{2+}\right)$, os quais, a partir de então, seguem atuando em vias diferentes e compartilhando açóes antioxidantes, anti-inflamatórias, antiapoptóticas e 
anti-proliferativas $6,7,10,11$ (FIGURA 1).

Dentre os produtos do catabolismo de heme, o CO era anteriormente conhecido como uma molécula letal em altas concentraçóes, cuja capacidade de se ligar à hemoglobina/mioglobina impedia a entrega de oxigênio aos tecidos, levando à hipóxia citotóxica. Atualmente, já tem sido descrito na literatura que o $\mathrm{CO}$, em baixas concentrações, desempenha açóes protetoras em diferentes modelos de doenças em roedores ${ }^{4,5,12-14}$, além de ajudar na aceitação de xenotransplante cardíaco $^{11}$, e possuir efeitos anti-inflamatórios em células de defesa como macrófagos e monócitos, modulando, portanto, o papel inicial da resposta imune. Essas açóes estão relacionadas à inibição seletiva da expressão de citocinas próinflamatórias, como o fator de necrose tumoral $\alpha(\mathrm{TNF} \alpha)$ e a interleucina-1 $\beta$ (IL-1 $\beta$ ), e com o aumento concomitante na produção de citocinas anti-inflamatórias, como a interleucina-10 (IL$10)^{4,11]}$. Outras ações incluem a participação na agregação plaquetária, suprimindo a trombose, e a diminuição da adesão de leucócitos, reduzindo a apoptose de células endoteliais ${ }^{7,11}$.

Outro produto do catabolismo da $\mathrm{HO}$ é o $\mathrm{Fe}^{2+}$ (FIGURA 1), uma molécula pró-oxidante e que, em altas concentraçóes intracelulares, pode causar dano à célula. $\mathrm{O} \mathrm{Fe}^{2+}$ liberado pela $\mathrm{HO}-1$ pode ser estocado na forma de ferritina ou exportado para fora da célula por meio da ferroportina, para que posteriormente se una à transferrina, um transportador que tem sua expressão induzida pelo acúmulo de ferro intracelular. As concentrações de ferro intracelular também podem ser reduzidas por meio de bombas dependentes de ATP, uma vez que moléculas de ferro livre podem participar da reação de Fenton, dando origem a radicais hidroxilas tóxicos, os quais podem oxidar lipídios e, consequentemente, danificar proteínas e o DNA ${ }^{7-8}$.

Por fim, a BVD gerada pela degradaçáo do substrato heme é reduzida a bilirrubina por uma enzima citosólica, a biliverdina redutase (FIGURA 1). A bilirrubina é uma molécula hidrofóbica que se associa à albumina para ser transportada pela corrente sanguínea, aonde é captada pelos hepatócitos e conjugada pela UDP (Uridina difosfato)-glicoruniltransferase ao ácido glicurônico, e subsequentemente excretada na bile ${ }^{8}$.

BARANANo et al. ${ }^{15}$ propuseram um ciclo onde a bilirrubina reage diretamente com espécies reativas de oxigênio, neutralizando sua propagação no ambiente intracelular. Nesse ciclo, a bilirrubina é oxidada convertendo-se a biliverdina e, subsequentemente, a biliverdina é então reduzida novamente a bilirrubina pela biliverdina redutase, sustentando o ciclo. Isso explicaria como as pequenas concentraçóes de biliverdina têm se mostrado como um potente agente antioxidante em diversos estudos $7,10,11,15$. De fato, vários estudos sugerem que a ação benéfica da $\mathrm{HO}-1$ em modelos experimentais de doença se deve aos seus produtos $5,13,11,14,16,17,18$.

Como uma característica comum dos indutores da HO-1 é o aumento nos níveis de espécies reativas de oxigênio (EROS $)^{19}$, e sabendo-se que uma única sessão de exercício físico induz um aumento absoluto de EROS, o exercício físico, por sua vez, seria capaz de induzir um aumento na expressáo de $\mathrm{HO}-1$ celular? Os estudos realizados até o momento indicam que sim, sendo tanto o exercício físico agudo (uma única sessão de exercício), como o exercício físico crônico (treinamento físico) capazes de modular a expressão de HO-1. Alguns autores têm demonstrado que diferentes tipos de exercício físico (e.g.: teste de esforço máximo em esteira ergométrica, realização de meia maratona, exercício excêntrico), assim como a duração e a intensidade do exercício realizado podem aumentar a expressáo da $\mathrm{HO}-1$, o qual poderia atuar de forma benéfica no organismo ${ }^{3,16,19-22}$. Portanto, é possível que parte dos efeitos benéficos do exercício físico se deva à ação da HO-1 e sua ação citoprotetora. 

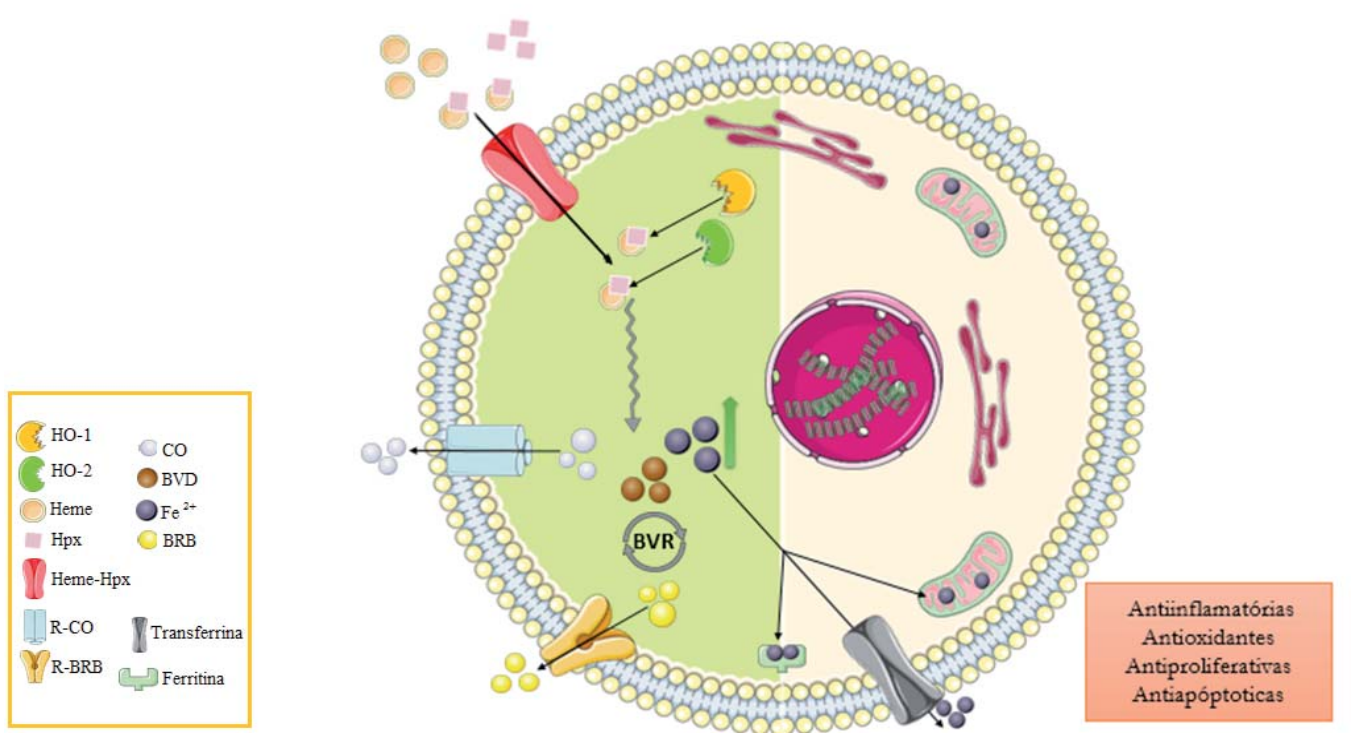

FIGURA 1 - Complexo Hemopexina/heme originando os três produtos resultantes da degradação do grupo heme. A hemopexina (Hpx) é uma glicoproteína que tem afinidade com o grupo heme. Uma vez ligada ao heme, a Hpx sofre uma mudança conformacional, permitindo a interação com um receptor específico (Heme-Hpx), expresso na membrana celular, e então é internalizada. No citosol, o heme é catabolizado pela hemoxigenase-1 (HO-1) ou hemoxigenase-2 (HO-2), dando origem aos produtos da degradaçáo do heme, que são: monóxido de carbono (CO), biliverdina (BVD) e o ferro ferroso $\left(\mathrm{Fe}^{2+}\right)$ que seguem atuando em vias diferentes compartilhando açóes citoprotetoras. BVR: biliverdina redutase, BRB: Bilirrubina, R-BRB: transportador de bilirrubina, R-CO: transportador de monóxido de carbono.

\section{Efeitos do exercício físico na HO-1}

Em um estudo realizado por Essing et al. ${ }^{20}$, animais foram submetidos a uma sessão aguda de exercício físico em esteira rolante, em duas diferentes intensidades, a fim de avaliar a expressão gênica de $\mathrm{HO}$ no músculo plantar nos tempos 0 e $24 \mathrm{~h}$ após a realização do exercício físico. Foi observado um aumento significante dos níveis de RNAm da HO-1 no músculo esquelético imediatamente após a sessão de exercício físico aeróbio $(0 \mathrm{~h})$, sugerindo que o aumento na expressão gênica da HO-1 tenha ocorrido ao longo da sessão de exercício físico. Além disso, nesse mesmo estudo, a expressão gênica da HO-1 apresentou-se aumentada no músculo tibial anterior durante períodos de contraçóes musculares repetitivas, induzidas por eletrodos implantados na camada muscular acima do nervo fibular anterior. $\mathrm{O}$ aumento nos níveis de RNAm de HO-1 induzido pelo exercício físico pode promover a síntese de proteínas de estresse, as quais têm por finalidade proteger as proteínas celulares de danos oxidantes ${ }^{20}$. De fato, Essing et al. ${ }^{20}$ sugerem que o aumento na produção de EROS durante o exercício físico poderia explicar o aumento na quantidade de heme celular e, consequentemente, o aumento resultante nos níveis de RNAm de HO-1, uma vez que um estudo in vitro ${ }^{21}$ demonstrou que níveis aumentados de EROS podem causar liberação de heme ligado à mioglobina. Sabendo-se que músculos vermelhos (com metabolismo predominantemente oxidativo) contém mais mioglobina quando comparados a músculos brancos (com metabolismo predominantemente glicolítico), o primeiro apresentaria um maior aumento na expressão de HO-1 pós-exercício, devido à sua necessidade de degradar/metabolizar o grupo heme celular.

De fato, Vesely et al. ${ }^{6}$ trataram ratos (injeção intraperitoneal) com solução hemina (indutor de estresse oxidativo com heme), e analisaram dois diferentes tipos de músculos esqueléticos: sóleo, de metabolismo predominantemente oxidativo, e o extensor longo dos dedos - EDL de metabolismo predominantemente glicolítico. 
Os autores demonstraram que o aumento na expressão de HO-1 nos músculos esqueléticos desses animais seguia um padrão específico para o tipo de fibra muscular, sendo que a HO-1 mostrou-se predominantemente expressa no músculo sóleo, enquanto sua expressão foi levemente aumentada no músculo EDL. O músculo sóleo contém uma alta porcentagem de fibras vermelhas e oxidativas, diferentemente do músculo EDL, o qual contém uma porcentagem maior de fibras brancas e glicolíticas. Dessa forma, os autores sugerem que a diferença encontrada na expressão de $\mathrm{HO}-1$ entre os músculos sóleo e EDL estaria relacionada à quantidade de mioglobina presente nesses músculos.

Veseley et al. ${ }^{6}$ e colaboradores ainda relatam que o músculo sóleo é mais resistente à lesão oxidativa do que o músculo EDL, e que essa resistência poderia ser explicada pela maior defesa antioxidante presente no primeiro, onde a $\mathrm{HO}-1$ desempenharia um importante papel na manutenção do estado redox muscular, devido à sua capacidade de gerar produtos como a bilirrubina, um potente agente antioxidante. Além disso, outro produto da açáo da HO-1, o CO, também poderia colaborar para a maior resistência à lesão encontrada no músculo sóleo em comparação ao EDL, já que este produto é capaz de modular o tônus vascular, diminuindo-o em condiçóes de estresse, e de participar do processo de relaxamento muscular ${ }^{13,17}$.

Em um outro estudo realizado por Fehrenbach et al. ${ }^{22}$ foi avaliada a influência de diferentes tipos de exercício físico na expressão da $\mathrm{HO}-1 \mathrm{em}$ leucócitos presentes no sangue periférico. $\mathrm{O}$ estudo foi composto por três grupos: 1) indivíduos do sexo masculino que foram submetidos a uma corrida de curta distância (metabolismo predominantemente anaeróbio); 2) indivíduos do sexo masculino submetidos a um exercício físico excêntrico (para indução de dano muscular); e 3) indivíduos do sexo masculino submetidos à corrida de longa distância (meia maratona, metabolismo predominantemente aeróbio). Os autores demonstraram que os indivíduos submetidos à corrida de curta distância e ao exercício físico excêntrico não apresentaram alterações significativas na expressão gênica de HO-1 nos leucócitos circulantes (linfócitos, monócitos e granulócitos) quando comparados aos indivíduos submetidos à meia maratona, os quais tiveram os níveis de HO-1 elevados em seus leucócitos após a realização da prova. Dessa forma, os autores sugeriram que o aumento nos níveis de expressão da HO-1 em leucócitos após o exercício físico prolongado (meia maratona) pode estar associado à proteção celular contra o aumento nos níveis de EROS e à necessidade de metabolização de heme, o que não ocorreu no exercício físico de curta distância, cujo metabolismo predominante é o anaeróbio. Já a ausência de alteração na expressão de HO-1 em leucócitos pelo exercício físico excêntrico comparado à meia-maratona pode ser devida a um menor esforço imposto pelo primeiro exercício e, consequentemente, a um menor aumento nos níveis de citocinas inflamatórias e de uma resposta menos sistêmica, evidenciada tanto por menores concentraçóes de lactato, como por menor contagem de leucócitos totais circulantes ${ }^{22}$. Por fim, os autores sugerem que as alteraçóes na expressão de HO-1 podem depender do tipo de exercício físico realizado, e também da intensidade e da duração do mesmo, modulando de forma diferencial os diversos tipos de leucócitos ${ }^{22}$. Ademais, é importante destacar que a realização de exercícios físicos aeróbios, como a meia-maratona, depende mais do recrutamento de músculos vermelhos, os quais possuem um maior percentual de fibras oxidativas e de mioglobina, o que também poderia explicar o aumento significativo de HO-1 nos leucócitos do grupo submetido à meia-maratona em detrimento aos demais.

Em outro estudo direcionado ao comportamento de células do sistema imune em resposta ao exercício físico aeróbio, NiEss et al. ${ }^{16}$ observou um aumento no conteúdo de HO-1 em linfócitos, monócitos e neutrófilos circulantes em indivíduos após a realização de meia-maratona, e essa expressão foi mantida por 3 e 24 h após o exercício nos monócitos e nos neutrófilos. Em contrapartida, o conteúdo de HO-1 nos linfócitos retornou aos valores basais $3 \mathrm{~h}$ após a realização do exercício físico, embora a porcentagem de linfócitos positivos para $\mathrm{HO}-1$ tenha permanecido elevada em todos os tempos avaliados. Apesar de não estarem completamente elucidados os mecanismos pelos quais o exercício físico aeróbio induz o aumento na expressão de HO-1, os autores atribuem a maior expressão de HO-1 nos neutrófilos e monócitos, em comparação aos linfócitos, à capacidade que tais células têm de desencadear uma resposta mais significativa e sistêmica, envolvendo maior produção de EROS, uma vez que em trabalho anterior ${ }^{23}$ foi sugerido existir uma via oxidativa de ativação do gene $\mathrm{HO}$, a via NF-KB, em monócitos expostos a peróxido de hidrogênio $\left(\mathrm{H}_{2} \mathrm{O}_{2}\right)$.

Tanto o estudo de Niess et al. ${ }^{16}$, quanto o de 
FeHrenbach et al. ${ }^{22}$ demonstram que a expressão de $\mathrm{HO}-1$ pode ser aumentada em leucócitos circulantes em indivíduos submetidos a exercício físico aeróbio prolongado (meia-maratona). Entretanto, a diferença entre ambos é o tempo de avaliação dessa expressáo, tendo o estudo de FeHrenbach et al. ${ }^{22}$ demonstrado o aumento da expressão de HO-1 imediatamente após a sessão de exercício físico, enquanto NiEss e colaboradores ${ }^{16}$ avaliaram essa expressão no tempo pós-exercício físico (3 e $24 \mathrm{~h}$ ). Assim, vimos que não somente o tipo de exercício físico, mas também o tempo pós-exercício (período de recuperação) interfere na expressão de HO-1 em leucócitos circulantes.

Além disso, o estudo de NiEss et al. ${ }^{16}$ mostrou haver alteração na expressão da HO-1 em níveis basais (em repouso) em indivíduos treinados quando comparados com indivíduos não treinados. Os autores demonstraram que o grupo treinado apresentou uma menor expressão de $\mathrm{HO}-1 \mathrm{em}$ repouso nos leucócitos circulantes, sendo esta alteração, portanto, um mecanismo de adaptação ao treinamento físico aeróbio (realizado de maneira regular), tendo em vista que tais indivíduos possuem um menor estado de pró-oxidação celular, e também uma redução na atividade oxidativa dos neutrófilos, os quais produzem menos EROS quando adaptados ao treinamento físico ${ }^{16}$.

Thompson et al. ${ }^{19}$ também com o objetivo de avaliar o efeito do exercício físico na expressão de HO-1 em leucócitos humanos, realizaram um estudo onde indivíduos participaram de 5 sessóes de exercício físico aeróbio ao longo de uma semana em esteira ergométrica. As sessóes tiveram duração de 75 minutos cada, realizadas a uma velocidade correspondente a $70 \%$ do $\mathrm{VO}_{2}$ máx. e, ao final delas, os indivíduos ficavam em repouso durante os mesmos 75 minutos. Foram realizadas coletas de sangue imediatamente, 1 e 2 horas após o término de cada sessão de exercício físico. Foram avaliadas as expressóes gênica e proteica de $\mathrm{HO}-1$ somente em linfócitos. Os autores demonstraram que o pico médio de expressão gênica da HO-1 nos linfócitos circulantes foi 2,7 vezes maior quando comparado ao repouso. Além disso, a expressão proteica de HO-1 aumentou significativamente nos linfócitos circulantes somente 2 horas após a realização do exercício em relação à situação de repouso.

O trabalho de Thompsom et al. ${ }^{19}$ corroboram com o estudo de Niess et al. ${ }^{16}$, onde ambos observaram aumento na expressão de $\mathrm{HO}-1 \mathrm{em}$ leucócitos circulantes após uma sessão de exercício físico aeróbio. Em contrapartida, não houve alterações, em ambos os estudos, na expressão da HO-1 nos linfócitos circulantes coletados durante o repouso. No entanto é importante destacar que no estudo de Niess ${ }^{16}$ os indivíduos possuíam melhor aptidão física quando comparados aos indivíduos do estudo de Tномрsом et al. ${ }^{19}$, os quais realizaram três diferentes tipos de exercício físico, sendo um deles a meia-maratona. Portanto, considerando os dados de ambos os estudos, é possível concluir que não só o tipo de exercício e sua duração, e o tempo de recuperação pós-exercício, podem alterar a expressão de HO-1 em leucócitos circulantes, mas também a intensidade em que o exercício é realizado. Da mesma forma, outros autores ${ }^{3,24}$ também sugerem que diferentes intensidades de exercício físico podem influenciar a homeostase redox e, consequentemente, a expressão da HO-1.

Com o objetivo de avaliar os efeitos de diferentes intensidades de exercício físico sobre o dano oxidativo celular e sobre a resposta antioxidante em linfócitos, Sureda et al. ${ }^{24}$ recrutaram indivíduos pré-profissionais para uma partida de futebol de 60 minutos. Com o auxílio de um pulsômetro foi determinada a intensidade do exercício, e então os indivíduos foram divididos em três grupos de acordo com o grau de intensidade, ou seja, indivíduos que realizaram exercício físico em intensidades baixa, média e alta. Eles observaram um aumento significativo na expressão gênica da HO-1 nos grupos de média e alta intensidades, sugerindo que a expressão de $\mathrm{HO}-1$ é aumentada de forma proporcional à intensidade do exercício físico e, consequentemente, à produção de $\mathrm{EROS}^{24}$. $\mathrm{O}$ exercício físico intenso aumenta a proliferação de linfócitos e a produção de EROS, e isso está relacionado a uma perturbaçáo da homeostase redox celular. Sureda et al. ${ }^{24}$ ainda sugere que o exercício físico é um excelente modelo para estudar a relação entre os pró-oxidantes e as defesas antioxidantes do organismo em indivíduos saudáveis.

Em outro estudo realizado por MARKOVITCH et al. ${ }^{3}$, os autores avaliaram se uma sessão de exercício físico (corrida em esteira, por 60 minutos, a uma intensidade correspondente a 57,7\% do $\mathrm{VO}_{2}$ pico) em humanos alteraria a expressão de $\mathrm{HO}-1$ em linfócitos e monócitos isolados do sangue periférico. Após a sessão de exercício, as células mononucleadas foram isoladas em cultura e foram expostas ao tratamento com $\mathrm{H}_{2} \mathrm{O}_{2}$, um indutor de estresse oxidativo, por 4, 6, 24 e 48 horas, a fim de determinar a expressão da 
HO-1 nessas células por citometria de fluxo. Contrariando os demais dados da literatura, observou-se uma diminuição na expressão de HO-1 em linfócitos extraídos do sangue periférico 2 horas pós-exercício e submetidos ao tratamento com $\mathrm{H}_{2} \mathrm{O}_{2}$ ex vivo. Contudo, os autores sugerem que essa diminuição na expressão de HO-1 nos linfócitos após a sessão de exercício pode significar uma adaptação positiva ao próprio exercício físico em resposta ao tratamento com o $\mathrm{H}_{2} \mathrm{O}_{2}$. Em outras palavras, uma vez que a sessão de exercício físico aumenta a expressão de proteínas de choque térmico e de antioxidantes endógenos, uma redução na expressão de HO-1 seria necessária para que houvesse um aumento na expressão de agentes oxidantes contra $\mathrm{o}_{2} \mathrm{O}_{2}$. $\mathrm{O}$ mesmo resultado foi encontrado em monócitos, porém este não foi significativo ${ }^{3}$.

Alguns autores ${ }^{25-26}$ também têm associado o aumento na expressão da HO-1 induzida pelo exercício físico à proteção em determinadas doenças. Como o exercício físico aeróbio induz aumento na expressão da $\mathrm{HO}-1$, seu papel como adjuvante no tratamento de doenças crônicas associadas ao estresse oxidativo tem sido estudada. Nesse sentido, MiYagi et al. ${ }^{26}$ com o objetivo de investigar se o exercício físico aeróbio seria capaz de diminuir injúria renal aguda induzida por cisplatina (um medicamento quimioterápico amplamente utilizado para o tratamento de diversos tipos de câncer, porém com um alto poder de resistência adquirida e efeitos colaterais), submeteram camundongos C57Bl6 a sessóes de exercício físico aeróbio em esteira rolante por 1 semana. Foi observado que os animais exercitados apresentaram um aumento na expressão da HO-1 no tecido renal quando comparados aos animais não-exercitados, estando

\section{Conclusão}

$\mathrm{O}$ interesse em estudar as funçôes da HO-1 vem aumentando substancialmente devido ao desempenho desta sobre a homeostase celular e devido às suas ações protetoras no organismo. Estudos conduzidos em humanos e em modelos animais vêm demonstrando a importância dessa enzima em diferentes lesões/doenças, assim como vem sendo demonstrado que o exercício físico pode modular a expressão de HO-1 de forma dependente esta resposta associada a um fenótipo protetor dos rins. Além disso, os autores demonstraram que animais com deficiência em HO-1 mostraramse mais suscetíveis à lesão renal causada pela cisplatina, enquanto indutores de $\mathrm{HO}-1$, como as metaloporfirinas, induziram aumento de vias antiapoptóticas, protegendo os rins de lesão induzida pela cisplatina ${ }^{26}$.

Analisando a HO-1 por outra vertente, alguns autores $^{27-28}$ apontam sua atividade como uma importante contramedida fisiológica adaptativa para o estresse oxidativo associado à doença de Alzheimer, uma desordem neurodegenerativa que prejudica a função cognitiva do cérebro, e que afeta milhóes de pessoas em todo o mundo. De fato, Kurucz et al..$^{25}$ demonstraram que a atividade da HO-1 se apresenta significativamente aumentada em animais idosos submetidos a um treinamento físico aeróbio em roda de atividade voluntária por três meses, quando comparados aos animais sedentários. A partir disso, os autores apontam que esse aumento na atividade da HO-1 pelo treinamento físico pode ser futuramente considerado como adjuvante ao tratamento da doença de Alzheimer e de distúrbios relacionados à mesma.

Embora os mecanismos pelos quais a $\mathrm{HO}-1$ protege as células contra um aumento exacerbado na produção de EROS ainda não estejam totalmente compreendidos, um aumento na expressão dessa enzima induzido pelo exercício físico, seja em células circulantes ou em tecidos, pode ter implicações potencialmente importantes e benéficas ao organismo ${ }^{29-30}$. Torna-se de extrema importância, portanto, uma melhor compreensão sobre os diferentes papéis assumidos pela enzima HO-1 no organismo, uma vez que a mesma tem a capacidade de diminuir o dano oxidativo celular, podendo auxiliar em futuras perspectivas clínicas, e tornar-se um alvo direcionado para melhoria de desordens sistêmicas, neurológicas e até mesmo musculares.

da duração, intensidade e tipo de exercício físico realizado. Esse aumento na expressão de $\mathrm{HO}-1$ pelo exercício físico aeróbio está muitas vezes associado a uma proteção celular, principalmente sobre as células de defesa do organismo (leucócitos), as quais são as primeiras a se manifestar em uma inflamação sistêmica, e que são continuamente expostas a agentes oxidantes. Entretanto, também já tem sido observado que o aumento na expressão 
de HO-1 pode estar associado à proteção de outros tipos celulares, como células renais, e em diferentes condiçôes, como em doenças neurológicas.

Em suma, o papel do exercício físico sobre as funções da HO-1 não está completamente elucidado, embora se saiba que o aumento na sua expressão contribui para uma melhora sistêmica do organismo. A contribuição dessa via de adaptação ao exercício físico necessita ser melhor investigada para que se torne possível a manipulação da mesma em condiçóes de saúde, como aumento de performance física, por exemplo, e também em condições patológicas, atuando como tratamento adjuvante em diferentes doenças. Além disso, considerando que a expressão de $\mathrm{HO}-1$ é dependente do tipo de fibra muscular, sendo mais expressa em fibras oxidativas do que em fibras glicolíticas, sugere-se que o exercício físico aeróbio possa ser a melhor escolha dentre os diferentes tipos de exercício quando o objetivo for o aumento da expressão de HO-1.

\title{
Agradecimentos
}

Os autores gostariam de agradecer à Smart Servier Medical Art por fornecer as imagens que compuseram a FIGURA 1.

\begin{abstract}
Hemoxigenase $(\mathrm{HO})$ is an enzyme that promotes degradation/metabolization of the heme group, generating three main products: carbon monoxide (CO), biliverdin (BVD) and ferrous iron ( $\left.\mathrm{Fe}^{2+}\right)$. One of the isoforms of $\mathrm{HO}$, Hemo-Oxygenase-1 (HO-1), has been extensively studied due to its cytoprotective properties, such as anti-inflammatory, antioxidant, antiapoptotic and antiproliferative functions in different cell types, animal models and humans. HO- 1 is activated under cell stress conditions like hypoxia, ultraviolet and heavy metals exposure, increased nitric oxide, inflammatory cytokines, ethanol, prostaglandins and during heat shock. In addition, $\mathrm{HO}-1$ is activated in response to exercise performed in different volume and intensities, promoting cryoprotection and cellular homeostasis. In the first part of this review, the $\mathrm{HO}$ cellular function and location will be discussed, while in the second part the effects of physical exercise on $\mathrm{HO}-1$ will be addressed, taking into consideration the differences between aerobic and anaerobic exercises; acute aerobic exercises (a single exercise session) performed at different volume and intensities; chronic aerobic exercise (exercise training), and the effect of aerobic exercise in chronic diseases.
\end{abstract}

KeYWORDS: HO-1; Exercise; Cytoprotection; Metabolism.

\section{Referências}

1. Tenhunen R, Marver HS, Schmid R. The enzymatic conversion of heme to bilirubin by microsomal heme oxygenase. Proc Natl Acad Sci USA, 1968;61(2):748-755.

2. Maines MD. The heme oxygenase system: update 2005. Antioxid Redox Signal Ant Redox Signal, 2005;7(11-12):17611766.

3. Markovitch D, Tyrrell RM, Thompson D. The effect of prior exercise on ex vivo induction of heme oxygenase-1 in human lymphocytes. Free Radic Res. 2007;41(10):1125-1134.

4. Otterbein LE, Bach FH, Alam J, Soares M, Lu HT, Wysk M. et al. Carbon monoxide has anti-inflammatory effects involving the mitogen-activated protein kinase pathway. Nat Med. 2000;6(4):422.

5. Ryter SW, Otterbein LE, Morse D, Choi AMK. Heme oxygenase/carbon monoxide signaling pathways: regulation and functional significance. Mol Cell Biochem. 2002;234 (1):249-263.

6. Veseley MJJ, Sanders R, Green CJ, Motterlini R. Fibre type specificity of haem oxygenase-1 induction in rat skeletal 
muscle. FEBS Lett, 1999:458(2):257-260.

7. Was H, Dulak J, Jozkowicz A. Heme oxygenase-1 in tumor biology and therapy. Curr Drug Targets. 2010;11(12):15511570 .

8. Rodrigues PMDA. Heme oxigenase-1 como um alvo terapêutico na sepse o papel da biliverdina. Rio de Janeiro. Dissertação (Mestrado em Biologia Celular e Molecular). Instituto Oswaldo Cruz; 2007.

9. Tanaka S, Akaike T, Fang J, Beppu T, Ogawa M, Tamura, F, et al. Antiapoptotic effect of haem oxygenase-1 induced by nitric oxide in experimental solid tumour. Br J Cancer, 2003;88(6):902.

10. Becker JC, Fukui H, Imai Y, Sekikawa A, Kimura T, Yamagishi H, et al. Colonic expression of heme oxygenase-1 is associated with a better long-term survival in patients with colorectal cancer. Scand J Gastroenterol. 2007;42(7):852-858.

11. Otterbein LE, Soares MP, Yamashita K, Bach FH. Heme oxygenase-1: unleashing the protective properties of heme. Trends immunol. 2003;24(8):449-455.

12. Motterlini R, Gonzales A, Foresti R, Clark Je, Green CJ, Winslow RM. Heme oxygenase-1-derived carbon monoxide contributes to the suppression of acute hypertensive responses in vivo. Circ. Res. 1998; 83(5):568-577.

13. Motterlini R, Otterbein LE. The therapeutic potential of carbon monoxide. Nat Rev Drug Discov. 2010;9(9):728.

14. Ryter SW, Choi AMK. Heme oxygenase-1/carbon monoxide: from metabolism to molecular therapy. Am J Respir Cell Mol Biol. 2009; 41(3):251-260.

15. Baranano DE, Rao M, Ferris CD, Snyder SH. Biliverdin reductase: a major physiologic cytoprotectant. Proc Natl Acad Sci. 2002;99(25):16093-16098.

16. Niess AM, Passek F, Lorenz I, Schneider EM, Dickhuth HH, Northoff, H, Fehrenbach E. Expression of the antioxidant stress protein heme oxygenase-1 (HO-1) in human leukocytes: acute and adaptational responses to endurance exercise. Free Radic Biol Med. 1999;26(1-2):184-192.

17. Sammut IA, Foresti R, Clark JE, Exon DJ, Vesely MJ, Sarathchandra P. et al. Carbon monoxide is a major contributor to the regulation of vascular tone in aortas expressing high levels of haeme oxygenase-1. Br J Pharmacol. 1998;125(7):14371444.

18. Zuckerbraun BS, Billiar TR, Otterbein SL, Kim PK, Liu F, Choi AM. Carbon monoxide protects against liver failure through nitric oxide-induced heme oxygenase-1. J Exp Med. 2003;198(11):1707-1716.

19. Thompson D, Basu-Modak S, Gordon M, Poore S, Markovitch D, Tyrrell, RM. Exercise-induced expression of heme oxygenase-1 in human lymphocytes. Free Radic Res. 2005;39(1):63-69.

20. Essing DA, Borger DR, Jackson DA. Induction of heme oxygenase-1 (HSP32) mRNA in skeletal muscle following contractions. Am J Physiol Cell Physiol. 1997;272(1):C59-C67.

21. Prasad MR, Engelman RM, Jones RM, Das DK. Effects of oxyradicals on oxymyoglobin. Deoxygenation, haem removal and iron release. Biochem J. 1989;263(3):731-736.

22. Fehrenbach E, Niess AM, Passek F, Sorichter S, Schwirtz A, Berg, A. et al. Influence of different types of exercise on the expression of haem oxygenase-1 in leukocytes. JSSM. 2003;21(5):383-389.

23. Kurata, SI, Matsumoto M, Nakajima H. Transcriptional control of the heme oxygenase gene in mouse M1 cells during their TPA induced differentiation into macrophages. J Cell Biochem. 1996;62(3):314-324.

24. Sureda A, Ferrer MD, Tauler P, Romaguera D, Drobnic F, Pujol P. et al. Effects of exercise intensity on lymphocyte $\mathrm{H} 2 \mathrm{O} 2$ production and antioxidant defences in soccer players. Br J Sports Med. 2009;43(3):186-190.

25. Kurucz A, Bombicz M, Kiss R, Priksz D, Varga B, Hortobágyi T, et al. Heme oxygenase-1 activity as a correlate to exercise-mediated amelioration of cognitive decline and neuropathological alterations in an aging rat model of dementia. BioMed Res. Int. 2018.

26. Miyagi MYS, Seelaender M, Castoldi A, de Almeida DC, Bacurau AVN, Andrade-Oliveira V. et al. Long-term aerobic exercise protects against cisplatin-induced nephrotoxicity by modulating the expression of IL-6 and HO-1. PLoS ONE. 2014;9(10):e108543.

27. Serini S, Calviello G. Reduction of oxidative/nitrosative stress in brain and its involvement in the neuroprotective effect of n-3 PUFA in Alzheimer's disease. Curr Alzheimer Res. 2016;13(2):123-134.

28. Verdile G, Keane KN, Cruzat VF, Medic S, Sabale M, Rowles J, et al. Inflammation and oxidative stress: the molecular connectivity between insulin resistance, obesity, and Alzheimer's disease. Mediators Inflamm. 2015;2015:17.

29. Halliwell B, Gutteridge JMC. Free radicals in biology and medicine. Oxford Science, 1999.

30. Weiss, SJ. Tissue destruction by neutrophils. N Engl J Med. 1989;320(6):365-376. 
ENDEREÇO

Patricia Chakur Brum

Laboratório de Fisiologia Celular e Molecular do Exercício Depto. de Biodinâmica do Movimento do Corpo Humano

Escola de Educação Física e Esporte

Submetido: 13/06/2019

Universidade de São Paulo

Aceito: 27/06/2019

Av. Professor Mello Moraes, 65 - Butantã

05508-030 - São Paulo - SP - Brasil

E-mail: pcbrum@usp.br

Rev Bras Educ Fís Esporte, (São Paulo) 2020 J ul-Set;34(3):523-31 • 531 